\title{
EFEITO DOS REGULADORES DE CRESCIMENTO AIB E ANA NO ENRAIZAMENTO DE MINIESTACAS DE CLONES DE Eucalyptus grandis $\mathrm{X}$ Eucalyptus urophylla ${ }^{1}$
}

\author{
Patrícia Bueno Goulart ${ }^{2}$, Aloisio Xavier ${ }^{3}$ e Narcisio Zeferino Cardoso ${ }^{4}$
}

\begin{abstract}
RESUMO - Este estudo teve como objetivo avaliar a eficiência dos reguladores de crescimento AIB e ANA no enraizamento de miniestacas de quatro clones de Eucalyptus grandis $\mathrm{x}$ E. urophylla. As miniestacas foram coletadas no minijardim clonal conduzido em sistema de hidroponia em canaletas. O delineamento experimental utilizado foi em blocos ao acaso, em arranjo fatorial $2 \times 5 \times 4$, constituído de dois reguladores de crescimento (AIB e ANA), cinco doses de AIB e ANA e quatro clones, em quatro repetições e parcelas compostas de 16 plantas/repetição. Foram feitas avaliações em casa de vegetação, casa de sombra e pleno sol, quanto ao porcentual de sobrevivência, altura, diâmetro de colo e massa seca da parte aérea e radicular das miniestacas enraizadas. Conclui-se que a utilização do AIB nas doses entre 500 e $2.000 \mathrm{mg} \mathrm{L}^{-1}$ mostrou-se mais eficiente do que o ANA nos quatro clones estudados.
\end{abstract}

Palavras-chave: Miniestaquia, estaquia e propagação vegetativa.

\section{EFFECT OF THE GROWTH REGULATORS IBA AND ANA ON THE ROOTING OF MINICUTTINGS OF Eucalyptus grandis $X$ Eucalyptus urophylla CLONES}

\begin{abstract}
The objective of the present work was to evaluate the efficiency of the growth regulators IBA and ANA on the rooting of minicuttings of four clones of Eucalyptus grandis $x \boldsymbol{E}$. urophylla. The minicuttings were collected in a clonal minigarden under a hydro phonic system in small gutters. The experiment was arranged in a randomized design with plots in a $2 \times 5 \times 4$ factorial constituted of two growth regulators (IBA and ANA), five doses of each growth regulator and four clones, in four repetitions and plots of 16 plants per repetition. The evaluations were carried out in a greenhouse, a shade house and in the open sun for survival rate, height, stem diameter and dry mass of the aerial and root parts of the rooted minicuttings. It was concluded that using IBA in doses between 500 and 2,000 $\mathrm{mg} \mathrm{L}^{-1}$ was more efficient than using ANA for the four clones studied.
\end{abstract}

Keywords: Minicutting, stem-cutting rooting and vegetative propagation.

\section{INTRODUÇÃO}

Nos últimos anos, notou-se grande evolução das pesquisas visando à maximização do enraizamento de estacas de clones de Eucalyptus, em que se perceberam avanços consideráveis nas técnicas de miniestaquia e microestaquia. No entanto, fundamentos biológicos da formação de raízes adventícias e o papel de substâncias promotoras e co-fatores no processo de enraizamento têm atraído não apenas a atenção dos pesquisadores, mas sendo também de interesse das empresas florestais no processo de produção comercial de plantas clonais.

\footnotetext{
${ }^{1}$ Recebido em 20.07.2007 e aceito para publicação em 22.08.2008.

${ }^{2}$ Programa de Pós-Graduação em Ciência Florestal da Universidade Federal de Viçosa (UFV). E-mail: <pbgoulart@uol.com.br>.

${ }^{3}$ Departamento de Engenharia Florestal da UFV. E-mail: <xavier@ufv.br>.

${ }^{4}$ International Paper do Brasil. E-mail:<narcisio.cardoso@ipaperbr.com>.
} 
A habilidade de enraizamento difere consideravelmente entre as espécies florestais, que podem ser classificadas em espécies de fácil propagação e espécies com respostas crescentes ao enraizamento, quando lhes são proporcionadas condições adequadas de controle ambiental e manejo da fonte de propágulo vegetativo; e aquelas espécies com resposta pequena ou nenhuma aos estímulos para enraizamento (XAVIER, 2002). Para o gênero Eucalyptus e entre os clones de uma mesma espécie, várias mudanças podem ser observadas, quanto ao porcentual de enraizamento, podendo variar de 0 a $100 \%$, conforme resultados observados na literatura (HIGASHI et al., 2000).

De forma geral, ao longo do desenvolvimento as plantas lenhosas sofrem modificações morfológicas e fisiológicas ao se mudarem da fase juvenil para a adulta. Sabe-se que a capacidade de enraizamento em muitas espécies diminui à medida que a planta expressa características de maturação. Entre os principais fatores que afetam a propagação vegetativa pelo enraizamento de estacas estão aqueles relacionados com o genótipo, com as condições fisiológicas da planta fornecedora das estacas, com o tipo de estaca, com a nutrição mineral (vigor vegetativo da planta-matriz e "status" nutricional do material coletado), com o tratamento das estacas (armazenamento, aplicação de reguladores de crescimento, antioxidantes e co-fatores) e com a manipulação das condições ambientais, quanto à luminosidade, umidade, temperatura e substrato (GREENWOOD e HUTCHISON, 1993; HARTMANN et al., 2002; TAIZ e ZEIGER, 2004).

As condições fisiológicas da planta doadora de propágulos dependem de um conjunto de fatores intrínsecos que poderão ou não estar atuando no metabolismo da planta, na ocasião da coleta de estacas (NORBERTO, 1999). Esses fatores influenciarão a rizogênese das referidas estacas. A formação de raízes adventícias é dependente da presença de certos níveis endógenos de substâncias de crescimento da planta, sendo algumas mais favoráveis que outras. Dependendo da espécie e do estado de maturação, entre outros fatores, como mencionado anteriormente, várias substâncias, quando aplicadas no propágulo, promovem ou inibem a iniciação de raízes adventícias.

Entre os reguladores de crescimento mais conhecidos e de interesse na propagação vegetativa de plantas, destacam-se as auxinas. Segundo Taiz e Zeiger (2004), a resposta da planta à auxina endógena ou aplicada pode variar com a natureza do tecido e com a concentração desse regulador de crescimento já presente no propágulo. Aplicada em órgãos isolados, a auxina, dependendo de sua concentração, pode aumentar a resposta rizogênica até certo ponto, após o qual ocorre efeito inibitório.

Com relação à aplicação de ácido indolbutírico (AIB), Wendling (1999) e Wendling et al. (2000b) verificaram em Eucalyptus que os melhores índices de enraizamento de miniestacas foram obtidos com doses de AIB variando de $1.000 \mathrm{mg} \mathrm{L}^{-1}$ a $3.000 \mathrm{mg}$ $\mathrm{L}^{-1}$. Também, Titon (2001) observou aumento nos índices de enraizamento e sobrevivência das miniestacas com maior eficiência nas doses entre 1.000 e $2.000 \mathrm{mg} \mathrm{L}^{-1}$, na maioria dos clones de Eucalyptus estudados.

Wendling (2002), trabalhando com clones de Eucalyptus grandis, verificou, entretanto, que a aplicação de AIB não resultou em aumento no enraizamento e sobrevivência das miniestacas, sendo observada influência negativa das doses acima de $500 \mathrm{mg} \mathrm{L}^{-1} \mathrm{em}$ alguns clones e algumas características estudadas. Alguns autores constataram que materiais juvenis, no entanto, não necessitam da aplicação de AIB para incrementar o enraizamento (ASSIS et al., 1992; COMÉRIO et al., 1996; XAVIER e COMÉRIO, 1996).

Pouco se conhece sobre a aplicação do ácido naftalenoacético (ANA) em miniestacas de essências florestais. Apenas Santos (2002), trabalhando com jequitibá-rosa (Cariniana estrellensis), mencionou que os melhores resultados de enraizamento foram obtidos utilizando $4.000 \mathrm{mg} \mathrm{L}^{-1}$ de ANA, aos 90 dias de idade.

Dessa forma, dada a atual importância da propagação clonal de Eucalyptus, este estudo teve como objetivo avaliar o efeito dos reguladores de crescimento AIB e ANA no enraizamento adventício de miniestacas de quatro clones de Eucalyptus grandis x E. urophylla.

\section{MATERIAL E MÉTODOS}

\subsection{Material experimental}

Foram utilizados quatro clones de Eucalyptus grandis x E. urophylla provenientes da empresa International Paper do Brasil, localizada no Município de Mogi Guaçu, São Paulo. O clima dessa região é do tipo Cwa (tropical, úmido e mesotérmico), segundo 
a classificação de Köeppen, com latitude de $22^{\circ} 21^{\prime} \mathrm{S}$, longitude de $48^{\circ} 58^{\prime} \mathrm{W}$ e altitude média de $639 \mathrm{~m}$. Apresenta precipitação média anual de $1.317 \mathrm{~mm}$ e temperatura média anual de $21^{\circ} \mathrm{C}$, com máxima média de $24{ }^{\circ} \mathrm{C}$ e mínima média de $16{ }^{\circ} \mathrm{C}$.

Para a seleção desses clones foram considerados os porcentuais de área plantada e de enraizamento desses materiais genéticos, dados esses fornecidos pelo Departamento de Pesquisa da referida empresa.

A partir de plantas obtidas pela técnica de miniestaquia, o minijardim clonal foi instalado no Viveiro Experimental da International Paper do Brasil, localizado em condições cobertas, constituído pelos quatro clones em estudo (H1, H2, H3 e H4).

\subsection{Manejo do minijardim clonal}

Conforme a técnica de miniestaquia (XAVIER e WENDLING, 1998; HIGASHI et al., 2000; ASSIS et al., 2004) e de acordo com os procedimentos de manejo adotados pela empresa, o minijardim clonal foi constituído de minicepas, obtidas pelo enraizamento de miniestacas oriundas de brotações de plantas propagadas pelo método da microestaquia. As miniestacas enraizadas, ao atingirem 10 a $12 \mathrm{~cm}$ de tamanho, tiveram seus ápices podados na altura de $8 \mathrm{~cm}$, constituindo, assim, as minicepas que forneceram as miniestacas (brotações) para realização do experimento.

O sistema de manejo do minijardim clonal adotado foi o utilizado comercialmente pela empresa e composto por canaletas de alumínio revestidas com fibra de vidro, sobre as quais permaneceram as minicepas, plantadas em tubetes dispostos em bandejas de isopor cobertas por plástico dupla fase. A irrigação e a nutrição mineral foram efetuadas através do sistema automatizado de fertirrigação por inundação, de maneira que somente o sistema radicular permanecia em contato com a solução nutritiva. A cada $1 \mathrm{~h}$ o sistema era acionado, irrigando por um período de 20 min e atingindo cerca de $6 \mathrm{~cm}$ de altura do tubete. Após esse período, a canaleta era esvaziada, e a solução nutritiva retornava à caixa de armazenagem da solução, sendo esta trocada a cada sete dias.

Diariamente eram mensurados a Ec (condutividade elétrica, usada para medir a quantidade de sais presentes na solução) e o pH da solução. Nesse período, a Ec variou de 2,00 a 2,40 mS cm-1 e o pH, de 3,05 a 5,76. Em 500 litros de solução nutritiva, adicionaram-se 20 g de nitrato de amônio, $200 \mathrm{~g}$ de nitrato de cálcio, 108 $\mathrm{g}$ de sulfato de amônio, $60 \mathrm{~g}$ de micronutrientes obtidos pelo produto Quelatec $A Z^{\circledR}$ e 740 g de Phytus Super $\mathrm{K}^{\circledR}$. O Quelatec $A Z^{\circledR}$ constitui-se de um quelato solúvel de micronutrientes composto por ferro, manganês, zinco e cobre na forma quelatada e por boro e molibdênio na forma mineral. Já o Phytus Super $\mathrm{K}^{\circledR}$ foi constituído de um fertilizante composto por NPK (00:40:20).

\subsection{Obtenção, preparo, plantio e enraizamento das miniestacas}

As miniestacas foram coletadas no minijardim clonal e acondicionadas em caixas de PVC transparente, mantidas fechadas. Para manter as condições de turgescência do material vegetativo, pulverizou-se água utilizando uma bomba costal, em intervalos de 10 min até a etapa de enraizamento, quando, então, as miniestacas foram preparadas com dimensões variando de 5 a $7 \mathrm{~cm}$ de comprimento e com um par de folhas, tendo a área foliar sido reduzida à metade de sua dimensão original.

Após o preparo das miniestacas, estas foram tratadas com os reguladores de crescimento AIB e ANA para, posteriormente, serem plantadas e colocadas para enraizamento na casa de vegetação climatizada. Foram utilizados os reguladores de crescimento AIB (ácido indolbutírico-Merck S.A.) e ANA (ácido naftalenoacético - Merck S.A.) em cinco concentrações (0, 500, 1.000, $2.000 \mathrm{e} 4.000 \mathrm{mg} \mathrm{L}^{-1}$ ), na formulação líquida, dissolvidos em hidróxido de potássio $(\mathrm{KOH})$ a $1 \mathrm{~mol} \mathrm{~L}^{-1} \mathrm{e}$ diluídos em água destilada autoclavada. As miniestacas tiveram suas bases $(2 \mathrm{~cm})$ mergulhadas na solução de regulador de crescimento por um período de $15 \mathrm{seg}$, antes de serem plantadas no substrato.

O período compreendido entre o preparo das miniestacas, seus tratamentos com reguladores de crescimento e plantio no substrato, na casa de vegetação, foi sempre inferior a $30 \mathrm{~min}$.

No enraizamento das miniestacas, utilizaram-se como recipientes tubetes plásticos de $55 \mathrm{~cm}^{3}$ de capacidade, contendo substrato constituído de partes iguais de vermiculita de granulometria fina e casca de arroz carbonizada. A nutrição mineral utilizada no substrato foi composta por 4,00 $\mathrm{kg} \mathrm{m}^{-3}$ de Fosmag 500B (MANAH, São Paulo) composto por $4 \%$ de N, 14\% de $\mathrm{P}, 7 \%$ de $\mathrm{K}, 14 \%$ de $\mathrm{Ca}, 9 \%$ de $\mathrm{S}, 2 \%$ de $\mathrm{Mg}$ e $0,5 \%$ de B; $5,40 \mathrm{~kg} \mathrm{~m}^{-3}$ de NPK (32:00:03) e 3,06 $\mathrm{kg} \mathrm{m}^{-3}$ de cloreto de potássio.

R. Árvore, Viçosa-MG, v.32, n.6, p.1051-1058, 2008

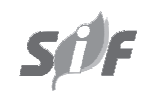


O processo de enraizamento das miniestacas foi conduzido em casa de vegetação climatizada (umidade relativa do ar $\geq 80 \%$ e temperatura em torno de $27^{\circ} \mathrm{C}$ ) com permanência de 25 dias. Posteriormente, as miniestacas foram transferidas para casa de sombra (permanência de 10 dias para aclimatização) e, finalmente, a pleno sol até completarem 50 dias de idade.

$\mathrm{O}$ delineamento experimental utilizado foi o inteiramente casualizado, em arranjo fatorial 2 x $5 \mathrm{x}$ 4 , constituído de dois reguladores de crescimento (AIB e ANA), cinco doses de AIB e ANA e quatro clones (H1, H2, H3 e H4), em quatro repetições e parcelas compostas de 16 plantas/repetição.

\subsection{Avaliações experimentais}

As avaliações das plantas foram realizadas quanto ao porcentual de sobrevivência das miniestacas na saída da casa de vegetação (aos 25 dias de idade), porcentual de enraizamento e altura das miniestacas na saída da casa de sombra (aos 35 dias de idade). Aos 50 dias de idade a pleno sol, avaliaram-se o porcentual de sobrevivência, a altura, o diâmetro de colo e a massa da matéria seca da parte aérea e da raiz das miniestacas enraizadas.

As avaliações de altura, diâmetro de colo, massa da matéria seca da parte aérea e do sistema radicular foram realizadas em quatro miniestacas/repetição selecionadas ao acaso em cada tratamento.

Os dados resultantes foram submetidos às análises de variância e regressão, utilizando-se os programas Statistica e Excel.

\section{RESULTADOS E DISCUSSÃO}

Com base nos resultados da análise de variância das características avaliadas (Tabela 1), observouse efeito significativo, pelo teste $\mathrm{F}(\mathrm{P}<0,05)$, das interações "clone $\mathrm{x}$ regulador de crescimento $\mathrm{x}$ tratamento", "clone x regulador de crescimento" e "clone x tratamento" sobre algumas características avaliadas, indicando respostas diferenciadas dos clones aos reguladores de crescimento e aos tratamentos adotados. Não houve diferença estatística $(P>0,05)$ na interação "tratamento x regulador de crescimento", em todas as características estudadas.

Quanto aos coeficientes de variação experimental encontrados, estes variaram de 20,0 até 25,9\%, evidenciando-se razoável precisão experimental em relação às características estudadas, de acordo com os valores encontrados na literatura (RIBAS, 1997; WENDLING et al., 2000a; TITON, 2001).

Tabela 1 - Resultados da análise de variância das características de sobrevivência das miniestacas na saída da casa de vegetação (SOBCV); do porcentual de enraizamento (ENRCS) e altura (ALTCS) das miniestacas na saída da casa de sombra; e da sobrevivência (SOB50), altura (ALT50), diâmetro de colo (DC50) e da massa de matéria seca da parte aérea (PSPA) e do sistema radicular (PSR) das plantas aos 50 dias de idade, em função das concentrações dos reguladores de crescimento AIB e ANA, dos quatro clones de Eucalyptus grandis x E. urophylla

Table 1 - Results of the Analysis of Variance (ANOVA) of survival data on minicuttings of four Eucalyptus grandis $x$ E. urophylla clones regarding greenhouse exit ( $S O B C V)$; shade house exit minicuttings rooting percentage (ENRCS) and height (ALTCS); survival rate (SOB50), height (ALT50), root collar diameter (DC50) as well as the dry mass of the aerial portion (PSPA) and root system (PSR) of the plants at 50 days of age, as a result of different concentrations of IBA and ANA growth regulators applications

\begin{tabular}{|c|c|c|c|c|c|c|c|c|c|}
\hline \multirow[t]{2}{*}{ Fontes de Variação } & \multirow[t]{2}{*}{ GL } & \multicolumn{8}{|c|}{ Quadrados Médios } \\
\hline & & $\begin{array}{c}\text { SOBCV } \\
(\%)\end{array}$ & $\begin{array}{c}\text { ENRCS } \\
(\%)\end{array}$ & $\begin{array}{c}\text { ALTCS } \\
(\mathrm{cm})\end{array}$ & $\begin{array}{c}\text { SOB50 } \\
(\%)\end{array}$ & $\begin{array}{c}\text { ALT50 } \\
(\mathrm{cm})\end{array}$ & $\begin{array}{l}\text { DC50 } \\
(\mathrm{mm})\end{array}$ & $\begin{array}{c}\text { PSPA } \\
(\mathrm{g})\end{array}$ & $\begin{array}{c}\text { PSR } \\
(\mathrm{g})\end{array}$ \\
\hline$\overline{\text { Clone }(\mathrm{C})}$ & 3 & $2763,26^{*}$ & $3269,12^{*}$ & $228,97^{*}$ & $6257,41^{*}$ & $561,41^{*}$ & $1,82^{*}$ & $261,75^{*}$ & $134,95^{*}$ \\
\hline Reg. Cres.(R) & 1 & $19,78^{\mathrm{ns}}$ & $6,10^{\mathrm{ns}}$ & $34,89^{*}$ & $1373,29^{*}$ & $27,47^{*}$ & $1,23^{*}$ & $1,62^{\mathrm{ns}}$ & $0,19^{\text {ns }}$ \\
\hline Trat. (T) & 4 & $3682,50^{*}$ & $4491,58^{*}$ & $14,17^{\mathrm{ns}}$ & $5060,00^{*}$ & $10,04^{\mathrm{ns}}$ & $0,13^{\mathrm{ns}}$ & $7,96^{\mathrm{ns}}$ & $1,55^{\mathrm{ns}}$ \\
\hline $\mathrm{C}^{*} \mathrm{R}$ & 3 & $112,22^{\mathrm{ns}}$ & $85,54^{\mathrm{ns}}$ & $8,28^{*}$ & $967,04^{*}$ & $12,78^{*}$ & $1,48^{*}$ & $0,31^{\mathrm{ns}}$ & $0,16^{\mathrm{ns}}$ \\
\hline $\mathrm{C}^{*} \mathrm{~T}$ & 12 & $1028,04^{*}$ & $1185,59^{*}$ & $8,89^{*}$ & $1183,75^{*}$ & $14,34^{*}$ & $0,20^{*}$ & $6,00^{\mathrm{ns}}$ & $1,27 \mathrm{~ns}$ \\
\hline $\mathrm{T} * \mathrm{R}$ & 4 & $88,75^{\mathrm{ns}}$ & $60,42^{\mathrm{ns}}$ & $4,13^{\mathrm{ns}}$ & $145,26^{\mathrm{ns}}$ & $7,85^{\mathrm{ns}}$ & $0,05^{\mathrm{ns}}$ & $1,54 \mathrm{~ns}$ & $0,49^{\mathrm{ns}}$ \\
\hline $\mathrm{C} * \mathrm{R} * \mathrm{~T}$ & 12 & $422,89^{*}$ & $338,42^{*}$ & $2,99^{\mathrm{ns}}$ & $487,71^{*}$ & $4,90^{\mathrm{ns}}$ & $0,05^{\mathrm{ns}}$ & $1,60^{\mathrm{ns}}$ & $0,87^{\mathrm{ns}}$ \\
\hline Resíduo & 120 & 101,39 & 100,34 & 1,67 & 105,88 & 3,39 & 0,10 & 24,69 & 11,97 \\
\hline Média Geral & - & 87,9 & 85,7 & 10,5 & 78,9 & 13,9 & 1,2 & 6,9 & 4,0 \\
\hline $\mathrm{CV}_{\text {exp }}(\%)$ & - & 20,8 & 22,4 & 25,7 & 24,8 & 24,4 & 20,0 & 25,9 & 25,7 \\
\hline
\end{tabular}

“ns" e "*” = não-significativo e significativo, respectivamente, a $5 \%$ de probabilidade, pelo teste $\mathrm{F}$.

R. Árvore, Viçosa-MG, v.32, n.6, p.1051-1058, 2008 


\subsection{Sobrevivência das miniestacas na saída da casa de vegetação}

A sobrevivência das miniestacas na saída da casa de vegetação, apresentada na Figura 1, indica que, no clone $\mathrm{H} 1$, os melhores resultados foram obtidos entre as doses de 500 e $1.000 \mathrm{mg} \mathrm{L}^{-1}$ de AIB, e no clone $\mathrm{H} 3$ os melhores resultados foram obtidos até a dose de $500 \mathrm{mg} \mathrm{L}^{-1}$ de AIB. No clone H2, a utilização de AIB demonstrou fitotoxicidade para a sobrevivência das miniestacas, mesmo com as menores doses aplicadas. Já no clone H4 a utilização do AIB não influenciou a sobrevivência das miniestacas.

De acordo Hartmann et al. (2002), a aplicação de auxinas em estacas, ao aumentar sua concentração, produz efeito estimulador na indução de raízes até um ponto máximo, a partir do qual qualquer acréscimo do nível de auxina se torna inibitório.

Quanto ao regulador de crescimento ANA (Figura 1), observou-se que nos clones $\mathrm{H} 1$ e $\mathrm{H} 4$ os melhores resultados de sobrevivência na saída da casa de vegetação foram obtidos até a dose de $500 \mathrm{mg} \mathrm{L}^{-1} \mathrm{de}$ ANA e nos clones $\mathrm{H} 2$ e H3, nas doses entre 500 e 1.000 $\mathrm{mg} \mathrm{L}^{-1}$ de ANA. De maneira geral, em todos os clones doses superiores a $1.000 \mathrm{mg} \mathrm{L}^{-1}$ de ANA acarretaram decréscimo na sobrevivência das miniestacas na saída da casa de vegetação, mas proeminente nos clones $\mathrm{H} 2$ e H4, que demonstraram fitotoxicidade para a sobrevivência das miniestacas.
Esses resultados estão de acordo com aqueles obtidos por Wendling (1999) e Titon (2001) para miniestaquia de Eucalyptus spp. Conforme Iritani et al. (1983), citados por Titon (2001), a avaliação da sobrevivência das miniestacas na saída da casa de vegetação não é garantia de êxito no seu enraizamento, porém é forte indicador de controle das condições ambientais (temperatura e umidade) da casa de vegetação.

\subsection{Enraizamento e altura das miniestacas na saída da casa de sombra}

Ao analisar os resultados de enraizamento das miniestacas na saída da casa de sombra aos 35 dias de idade (Figura 2), notou-se em todos os clones resultados semelhantes aos encontrados na saída da casa de vegetação (Figura 1), tanto utilizando AIB quanto ANA; não sendo verificadas diferenças estatísticas entre os reguladores de crescimento quanto ao enraizamento na saída da casa de sombra.

Observou-se no clone $\mathrm{H} 1$ efeito positivo da aplicação de AIB e ANA no enraizamento de miniestacas com maiores valores entre as doses de 1.000 a 2.000 $\mathrm{mg} \mathrm{L}^{-1}$ de AIB e até $500 \mathrm{mg} \mathrm{L}^{-1}$ de ANA. O clone H2 apresentou decréscimos acentuados nos porcentuais de enraizamento mesmo nas menores doses aplicadas de AIB e ANA, demonstrando maior sensibilidade ao uso desses reguladores de crescimento.
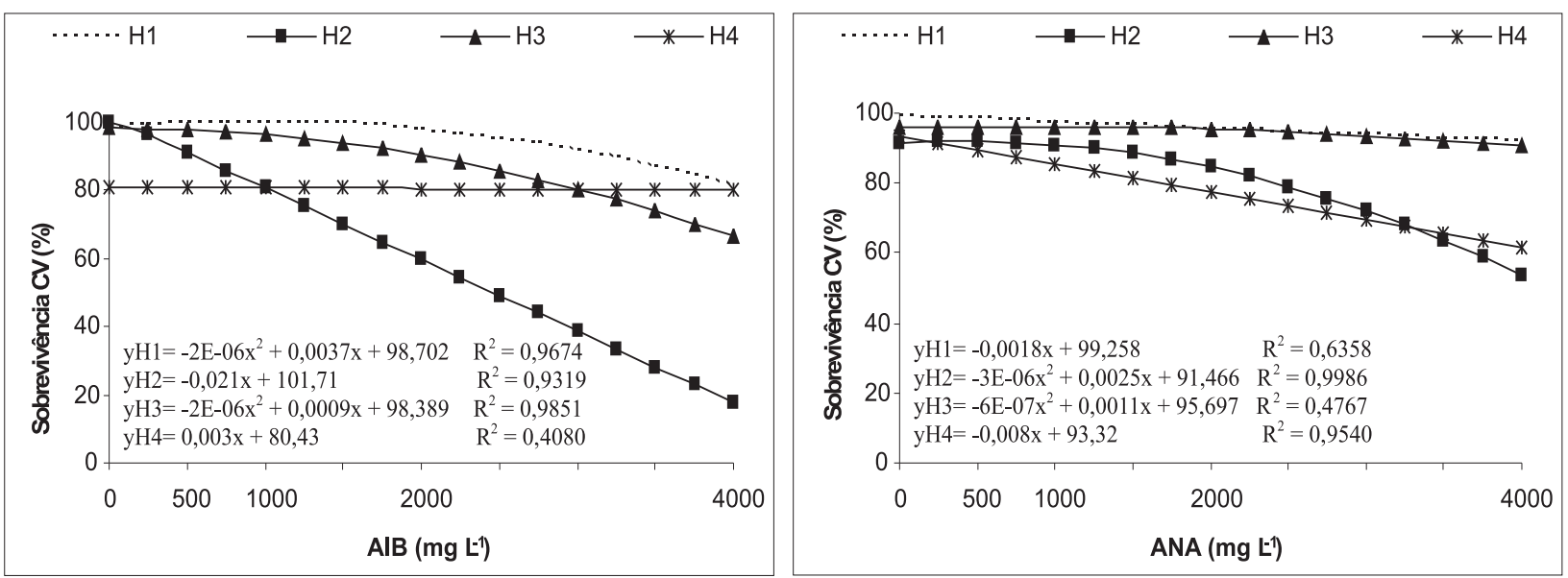

Figura 1 - Sobrevivência das miniestacas na saída da casa de vegetação, aos 25 dias de idade, em função da aplicação dos reguladores de crescimento AIB e ANA, dos quatro clones de Eucalyptus grandis x E. urophylla.

Figure 1 - Minicuttings of four Eucalyptus grandis $x$ E. urophylla clones greenhouse exit survival, at 25 days, as a result of IBA and ANA growth regulators applications.

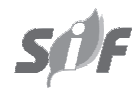

R. Árvore, Viçosa-MG, v.32, n.6, p.1051-1058, 2008 

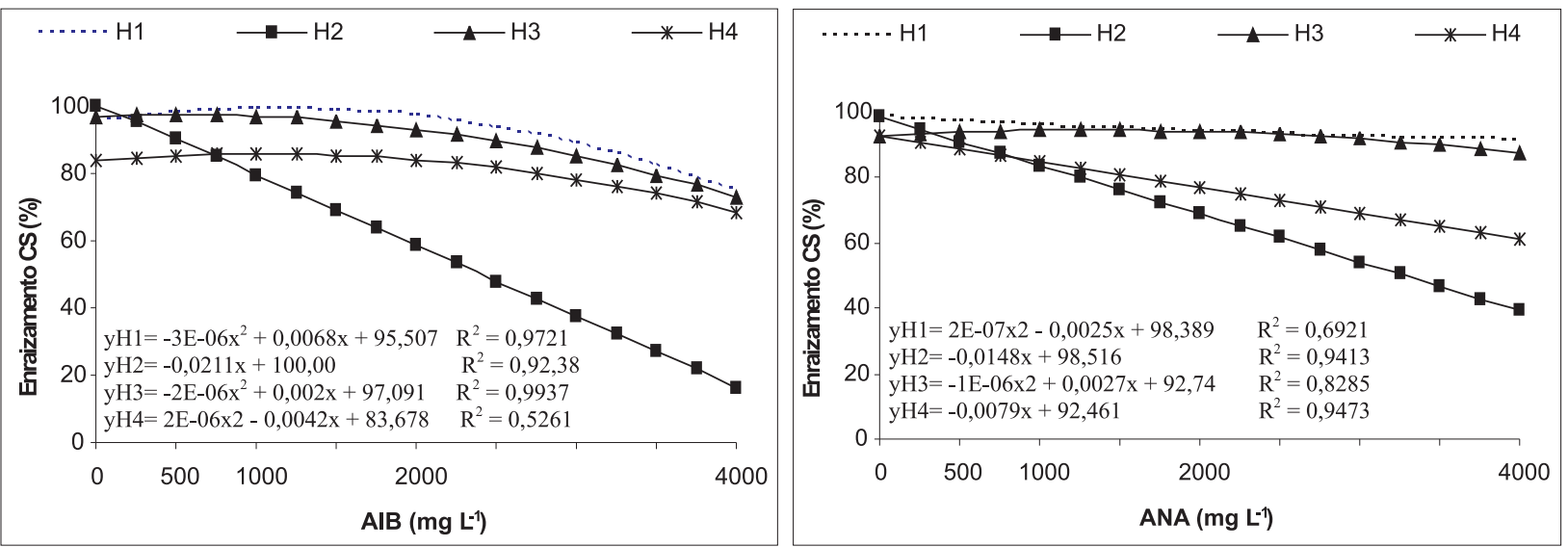

Figura 2 - Enraizamento das miniestacas na saída da casa de sombra, aos 35 dias de idade, em função da aplicação dos reguladores de crescimento AIB e ANA, dos quatro clones de Eucalyptus grandis x E. urophylla.

Figure 2 - Minicuttings of four Eucalyptus grandis $x$ E. urophylla clones shade house exit rooting, at 35 days, as a result of IBA and ANA growth regulators.

O enraizamento das miniestacas em resposta à aplicação de 0 a $1.000 \mathrm{mg} \mathrm{L}^{-1}$ de AIB apresentou-se pouco diferenciado no clone $\mathrm{H} 3$, ocorrendo decréscimos a partir dessa dosagem. Com o uso de ANA, os melhores resultados no clone $\mathrm{H} 3$ foram de 1.000 a $2.000 \mathrm{mg} \mathrm{L}^{-1}$ de ANA.

O clone $\mathrm{H} 4$ apresentou comportamento semelhante ao do $\mathrm{H} 3$ utilizando $\mathrm{AIB}$, porém o $\mathrm{H} 4$ exibiu decréscimos acentuados nos porcentuais de enraizamento a partir da dose de $2.000 \mathrm{mg} \mathrm{L}^{-1}$ de AIB. Já quanto à utilização do ANA, o comportamento do clone $\mathrm{H} 4$ foi semelhante ao $\mathrm{H} 2$, apresentando, mesmo nas menores doses aplicadas de ANA, sensibilidade ao uso desse regulador de crescimento.

Durante o tempo de permanência na casa de sombra, observou-se mortalidade somente das miniestacas que apresentavam sistema radicular muito pouco desenvolvido ou que não possuíam raiz alguma na saída da casa de vegetação (aos 25 dias de idade), não sendo verificado mortalidade causada por outros fatores.

Resultados semelhantes a esses foram obtidos em outras espécies de Eucalyptus, observando-se elevados índices de enraizamento ao utilizar a técnica da miniestaquia (ASSIS et al., 1992; XAVIER e COMÉRIO, 1996; WENDLING et al., 2000a; TITON, 2001).

Com relação às médias da altura das miniestacas aos 35 dias de idade, em função dos tratamentos não houve efeito significativo (Quadro 1). O clone H1, entre todos, foi o que apresentou maior altura de planta, nas doses entre 1.000 e $2.000 \mathrm{mg} \mathrm{L}^{-1} \mathrm{de}$ AIB e de 0 a $500 \mathrm{mg} \mathrm{L}^{-1}$ de ANA. Nos clones H2, H3 e H4, os resultados de médias da altura das miniestacas foram semelhantes tanto utilizando AIB quanto ANA, sendo no clone $\mathrm{H} 2$ os melhores resultados obtidos com a não-aplicação dos reguladores de crescimento.

\subsection{Sobrevivência, altura, diâmetro de colo e matéria seca das miniestacas enraizadas}

Com relação à sobrevivência das plantas a pleno sol aos 50 dias de idade (Figura 3), o comportamento apresentado pelos clones, ao utilizar o AIB, foi semelhante ao enraizamento na saída da casa de sombra (Figura 2). No entanto, ao se utilizar o ANA houve maiores variações entre as doses e decréscimos mais acentuados nos porcentuais de sobrevivência das plantas a pleno sol.

Os clones H1, H2 e H3 apresentaram boa capacidade de enraizamento adventício. Ao analisar a sobrevivência das miniestacas a pleno sol, os melhores resultados, ao se aplicar AIB, foram obtidos entre as doses de 500 e $2.000 \mathrm{mg} \mathrm{L}^{-1}$ de AIB no clone $\mathrm{H} 1$; de 0 a $\quad 500$ $\mathrm{mg} \mathrm{L}^{-1}$ de AIB no clone $\mathrm{H} 2$; e de 500 a $1.000 \mathrm{mg} \mathrm{L}^{-1}$ de AIB no H3.

O clone H4 apresentou decréscimo na sobrevivência das miniestacas a pleno sol quando foram aplicados AIB e ANA. Quanto se utilizou o ANA, os clones H1, $\mathrm{H} 2$ e H3 exibiram comportamento semelhante ao do H4, porém com maiores índices de sobrevivência de miniestacas a pleno sol. 

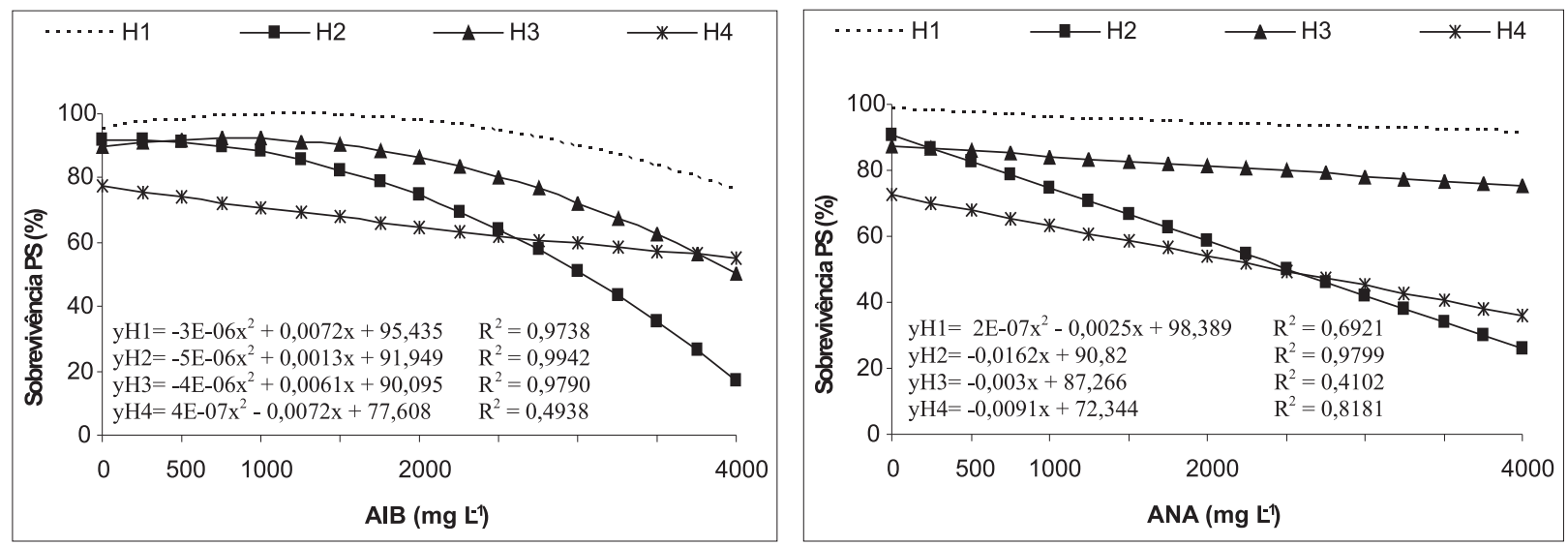

Figura 3 - Sobrevivência das miniestacas a pleno sol, aos 50 dias de idade, em função da aplicação dos reguladores de crescimento AIB e ANA, dos quatro clones de Eucalyptus grandis x E. urophylla.

Figure 3 - Minicuttings of four Eucalyptus grandis $x$ E. urophylla clones survival in full sun, at 50 days of age, as a result of IBA and ANA growth regulators.

A hipótese era de que a aplicação de AIB e, ou, ANA promovesse aumento nos índices de enraizamento e sobrevivência nas miniestacas, o que se confirmou na maioria dos clones estudados, quando foram aplicadas doses acima de $500 \mathrm{mg} \mathrm{L}^{-1}$ de AIB. De certa forma, esses resultados concordam com os obtidos por Wendling et al. (2000b) utilizando miniestacas de Eucalyptus spp., os quais verificaram aumento nos índices de enraizamento e sobrevivência com aplicação de doses entre 0 e $2.000 \mathrm{mg} \mathrm{L}^{-1}$ de AIB.

A diversidade de respostas dos clones à utilização de AIB e ANA pode estar associada, principalmente, às diferenças genotípicas e às condições de maturação do material (CHUNG e LEE, 1994; WILSON, 1994; KAMLESH et al., 1995).

Tanto utilizando AIB quanto ANA, os clones estudados apresentaram crescimento em altura e em diâmetro de colo das miniestacas a pleno sol diferenciado entre eles. No entanto, dentro de cada clone não foram observadas diferenças estatísticas entre as doses desses reguladores de crescimento.

Os resultados de peso de matéria seca da parte aérea foram semelhantes aos de peso de matéria seca do sistema radicular das plantas a pleno sol. A aplicação de AIB e ANA não surtiu efeito significativo nos tratamentos de todos os clones.

\section{CONCLUSÕES}

De acordo com os resultados e as condições em que foi realizado o experimento, conclui-se que:
* Os clones estudados responderam mais eficientemente às aplicações de AIB do que às de ANA, quanto às características avaliadas.

* Doses acima de $500 \mathrm{mg} \mathrm{L}^{-1}$ de AIB foram mais eficientes nos quatro clones estudados; no entanto, a partir de $2.000 \mathrm{mg} \mathrm{L}^{-1}$ de $\mathrm{AIB}$, notaram-se certos níveis de toxicidade em alguns clones.

\section{AGRADECIMENTOS}

À empresa International Paper do Brasil, pela oportunidade de realização deste trabalho, pela disponibilização do material genético (clones) e pelo apoio financeiro, de pessoal e de infraestrutura.

\section{REFERÊNCIAS}

ASSIS, T. F.; ROSA, O. P.; GONÇALVES, S. I. Propagação por miniestaquia. In: CONGRESSO FLORESTAL ESTADUAL, 7., 1992, Nova Prata. Anais... Santa Maria: Universidade Federal de Santa Maria, 1992. p.824-836.

ASSIS, T.; FETT-NETO, A. G.; ALFENAS, A. C. Current techniques and prospects for the clonal propagation of hardwoods with emphasis on Eucalyptus. In: WALTERS, C.; CARSON, M (Eds.). Plantation forest biotechnology for the $21^{\text {st }}$ Century, Research Signpost. India, 2004. p.303-333.

R. Árvore, Viçosa-MG, v.32, n.6, p.1051-1058, 2008 
CHUNG, D. Y.; LEE, K. J. Effects of clones, ortet age, crown position and rooting substance upon the rooting of cuttings of Japanese larch (Larix leptolepis S. et Z. Gordon). Forestry Genetics Research Institute, v.83, n.2, p.205-210, 1994.

COMÉRIO, J.; XAVIER, A.; IANELLI, C. M. Microestaquia: um novo sistema de produção de mudas de Eucalyptus na Champion. In: ENCONTRO TÉCNICO FLORESTAL, 7., 1996, Belo Horizonte. Anais... Piracicaba: ABRACAVE, 1996. 6p.

GREENWOOD, M. S.; HUTCHISON, K. W. Maturation as a development process. In: AHUJA, M. R.; LIBBY, W. J. (Eds.). Clonal forestry: genetics and biotechnology. Budapest: SpringerVerlag, 1993. p.14-33.

HARTMANN, H. T. et al. Plant propagation: principles and practices. 7.ed. New Jersey: Prentice-Hall, 2002. 880p.

HIGASHI, E. N.; SILVEIRA, R. L. A.; GONÇALVES, A. N. Evolução do jardim clonal de eucalipto para a produção de mudas. IPEF Notícias, v.24, n.148, p.4-6, 2000.

KAMLESH, K. et al. Effect of auxins and carbendazim on rooting of juvenile and mature stem cuttings of Grewi optiva. Indian Journal of Forestry, v.18, n.1, p.61-65, 1995.

LIMA, C. C. M. Uso de aditivos e cofatores na rizogênese de plântulas de Eucalyptus grandis Hill in vitro. 1998. 99f. Dissertação (Mestrado em Ciências Florestais) - Escola Superior de Agricultura Luiz de Queiroz, Piracicaba, 1998.

NORBERTO, P. M. Efeitos da época de poda, cianamida hidrogenada, irrigação e ácido indolbutírico na colheita antecipada e enraizamento de estacas de figueira (Ficus carica L.). 1999. 89f. Dissertação (Mestrado em Fitotecnia) Universidade Federal de Lavras, Lavras, 1999.

RIBAS, K. C. Interações entre auxina e cofatores do enraizamento na promoção do sistema radicular em estacas de Eucalyptus grandis W. Hill ex Maiden. 1997. 150f. Tese (Doutorado em Ciências Biológicas) - Universidade Estadual de São Paulo, Botucatu, 1997.

R. Árvore, Viçosa-MG, v.32, n.6, p.1051-1058, 2008
SANTOS, G. A. Propagação vegetativa de mogno, cedro-rosa, jequitibá-rosa e angico-vermelho por miniestaquia. 2002. 75f. (Monografia de Graduação) Universidade Federal de Viçosa, Viçosa, MG, 2002.

TAIZ, L.; ZEIGER, E. Fisiologia vegetal. Porto Alegre: Artmed, 2004. 719p. (Tradução).

TITON, M. Propagação clonal de Eucalyptus grandis por miniestaquia e microestaquia. 2001. 65f. Dissertação (Mestrado em Ciência Florestal) - Universidade Federal de Viçosa, Viçosa, MG, 2001.

WEndling, I. Propagação clonal de híbridos de Eucalyptus spp. por miniestaquia. 1999. 70f. Dissertação (Mestrado em Ciência Florestal) - Universidade Federal de Viçosa, Viçosa, MG, 1999.

WENDLING, I. et al. Propagação clonal de híbridos de Eucalyptus spp. por miniestaquia. Revista Árvore, v.24, n.2, p.181-186, 2000a.

WENDLING, I. et al. Efeito do regulador de crescimento AIB na propagação de clones de Eucalyptus spp. por miniestaquia. Revista Árvore, v.24, n.2, p.187-192, 2000 b.

WENDLING, I. Rejuvenescimento de clones de Eucalyptus grandis por miniestaquia seriada e micropropagação. 2002. 98f. Tese (Doutorado em Ciência Florestal) - Universidade Federal de Viçosa, Viçosa, MG, 2002.

WILSON, P. J. Contributions of the leaves anda auxillary shoots to rooting in Eucalyptus grandis Hil a Maid. stem cuttings. Journal of Horticultural Science, v.69, n.6, p.999-1007, 1994.

XAVIER, A., COMÉRIO, J. Microestaquia: uma maximização da micropropagação de Eucalyptus. Revista Árvore, v.20, n.1, p.9-16, 1996.

XAVIER, A.; WENDLING, I. Miniestaquia na clonagem de Eucalyptus. Viçosa, MG: SIF, 1998. 10p. (Informativo Técnico SIF, 11).

XAVIER, A. Silvicultura clonal I: Princípios e técnicas de propagação vegetativa. Viçosa, MG: Universidade Federal de Viçosa, 2002. 64p. (Caderno Didático, 92). 